\title{
Social Science and Social Struggle: Understanding the Necessary Confluence of Scholarship and Political Commitment
}

\author{
Michael Clow St. Thomas University
}

Résumé

Sociologues et historiens évitent de reconnaître que leur engagement politique joue un rôle dans leur explication de la société. Mais nous savons tous que c'est le cas. Sommesnous de mauvais scientifiques? Non, pas d'après l'école d'Edinburgh, selon laquelle toute théorie scientifique réussie est simplement une connaissance pratique, influencée par la rencontre entre les fins humaines et le monde empirique. La connaissance pratique implique toujours l'application incertaine et tâtonnante de ressources intellectuelles tirées de solutions exemplaires à de nouvelles situations. La praxie est bien la seule façon d'atteindre la connaissance. Quelles que soient ses réussites, toutefois, la connaissance pratique est une «connaissance de terrain » ayant des limites théoriques et empiriques; elle ne peut entraîner une compréhension sure des processus de génération produisant ce que nous voyons. Ce qui distingue l'étude de la société de celle de la nature est le caractère si profondément et manifestement divergeant des objectifs politiques des traditions de recherche qui s'affrontent.

Les implications? Tout d'abord, nous devrions douter qu'il existe une certitude théorique coulée dans le roc, pour nous ou pour d'autres. Dogmatisme et sectarisme sont indéfendables épistémologiquement, selon l'école d'Edinburgh. Le débat scientifique y gagnerait, si nous dévoilions nos orientations politiques aussi clairement que nos conception et méthodologie de recherche. Et si nous exigions que chacun en fasse autant. Entre personnes de bonne volonté, ceci pourrait être possible d'un camp à l'autre dans la même tradition et même par delà les obstacles idéologiques. Dans le domaine des affaires publiques, la perspective d'Edinburgh suggère que, pour déplacer les assises du débat et cadrer/recadrer les questions, il faut reconnaître implicitement que la connaissance sociale est façonnée par ses objectifs politiques et qu'on ne peut simplement s'en tenir aux faits, rien qu'aux faits. 


\title{
Social Science and Social Struggle: \\ Understanding the Necessary Confluence of Scholarship \\ and Political Commitment
}

\begin{abstract}
Social scientists and historians are wary to acknowledge that political commitments play a part in their explanations of society. But we all know they do. Are we poor scientists? Not according to the Edinburgh School, which argues all successful scientific theories are but practical knowledge, shaped by the encounter of human purpose and empirical world. Practical knowledge always involves the uncertain, trial and error application of the intellectual resources drawn from exemplary solutions to new situations. Praxis is the only valid path to knowledge. But no matter how successful, practical knowledge is a theoretically and empirically limited 'working knowledge' which cannot produce sure understanding of the generative processes producing what we see. What distinguishes studies of society from those of Nature is that the political purposes of conflicting scholarly traditions are so deeply and manifestly divergent.
\end{abstract}

Implications? Above all we should be skeptical about any strong claims to theoretical certainty, on our part or by others. Dogmatism and sectarianism are epistemologically untenable in the Edinburgh view. Scientific debate would be advanced if we were as open about our political orientations as we are enjoined to be about research design and methodology. And demanded the same of others. This may be possible across 'camps' in the same tradition and even ideological barriers, where goodwill prevails. In the public sphere the Edinburgh perspective suggests the shifting of the grounds of debate and the framing/reframing of issues requires a tacit recognition that social knowledge is shaped by its political purposes and cannot simply be 'the facts m'am, just the facts.' 


\section{Social Science and Social Struggle: \\ Understanding the Necessary Confluence of Scholarship \\ and Political Commitment}

\section{Introduction}

The pose of 'objectivity' is a part of the armour of the scholarly trade. Whether on the Left, Right or the Centre, social scientists and historians are loath to acknowledge that political and ethical commitments play a part in shaping their explanations of society. This isn't surprising, for to do so risks casting the most serious doubt on the credibility of our work. Imagine declaring one's explanation of society is based on political judgments in an argument with someone who claims not to have any political axe to grind, but to be 'objective'. On the other hand, who still believes in the achievability of 'objectivity'? We all can see the role values and political judgments play in the theories of our ideological opponents. And our opponents see the influence of political judgment in our work.

Those of us on the Left live the paradox directly. We, as did Marx, insist that ours is a scientific study of society - we want to believe we can present an accurate understanding of the world as it is, and what it can be. But we also all hope to live by Marx's dictum that the point of scholarship is not merely to understand the world but to change it. Are these goals compatible? Does the presence of political judgment and commitment in our work mark us as poor social scientists? Or even that 'social science' is a non-sequitur?

Few of us do more than sideslip this issue. I propose we confront it squarely. In doing so, I will rely on the Edinburgh School of the sociology of scientific knowledge. Using the light they throw on the connection between purpose and knowledge in the natural sciences, I will argue that social science (and historical) scholarship is inevitably tied to political judgment and that this situation does not cripple work in our disciplines. But it does pose practical problems for how we conduct scientific debate, and how we present ourselves in political life as scholar-activists.

\section{Science, Objectivity and Scientific Knowledge}

The meaning and import of 'objectivity' lies in the role it is thought to play within a theory of knowledge and a view of scientific inquiry that we might call "scientific realism" (Tudor, 2007; Marshall, 1994: 439). The short form of this theory of knowledge is familiar to everyone: Science is both an empirical and a theoretical endeavour that aims to explain the phenomena under study in terms of their causes and effects. Scientific theory develops from insights arising from careful observation of the object of study. The validity of a theory is judged in terms of its ability to account for observations made of the object of study, and to successfully predict new observations (Newton, 1993: 4). The best kind of observations are those made within the highly controlled conditions of experiment, but many natural sciences (meteorology, geology, much of astrophysics) have to rely on observing the world in its natural complexity. One can never really prove a theory - for one cannot know whether the flaw in a theory won't be found in the next set of empirical tests. But it stands to reason that a theory that has the overwhelming weight of evidence over 


\section{Social Science and Social Struggle: \\ Understanding the Necessary Confluence of Scholarship and Political Commitment}

a long period of time behind it is firmly on the 'right track' in its explanation of how the world works. The "veracity" of scientific theory is understood "to mean that the claim in question is a direct representation of a reality that exists outside of, and independent from, our perceptions of it" (Eriksson, 2007). The strongest indication of being theoretically on the right track to truthfully understanding the causal processes of the world is the degree to which a scientific theory has guided our ability to manipulate natural forces through technology.

This realist model, in fact, requires more assumptions, both regarding ontology - the nature of reality itself - and epistemology. First, it is assumed that reality - the world - exists independent of our knowledge of it (Marshall, 1994). Secondly, it is assumed that there are "real causal powers and mechanisms" at play which may not be entirely or directly visible but which cause the phenomena we can experience as observers (Marshall, 1994: 439). It is these underlying causal objects, properties, forces and processes "of which science seeks knowledge" (Marshall, 1994: 439), and which the development of theory is intended to correctly infer (Tudor, 2007). Epistemologically, it is assumed that we can accurately observe the phenomena of the world (though all the effort put into teaching research design and methods suggests it is not an automatic achievement). Accurate observation inspires explanatory insight, and offers support, correction or refutation of the explanatory claims made by theory. Careful, accurate observation of the world, this model assumes, allows us to develop explanations which more and more closely reflect the processes of Nature-itself, that is the real, often invisible causal objects, forces and processes that create the observable world (Eriksson, 2007). J.W. Grove insisted on just this ability in plain language when he claimed that through science, "the world is knowable (albeit imperfectly) by us, as it actually is and not merely as appearance" (1989: 5).

For this model of the generation of knowledge to have any credibility, we must be able to reliably and accurately observe the phenomena of the object of our study, either directly with the senses or with instruments designed to reliably extend the senses - if not by fallible individuals acting alone, then by the collectivity of scientists involved in scientific debate about experimental findings and theory.

It is at this point that 'objectivity' enters the argument. Accomplishing clear and accurate observation has usually been understood to require a disinterested and impartial relationship to the phenomena under study, as well as honesty and completeness in reporting observations. To achieve this 'objectivity', it has usually been argued, requires the absence of assumptions and interests that might shape, distort or occlude accurate observation of the phenomena - the ability to observe phenomena without interpreting them. This latter, and central, connotation is inscribed in the famous instruction of the detective Sgt. Friday to his interviewees in Dragnet: "Just the facts, M'am, just the facts." 


\section{Social Science and Social Struggle: \\ Understanding the Necessary Confluence of Scholarship \\ and Political Commitment}

It was Sgt. Friday, the expert detective, who would supply the interpretation, and then test it against the accumulated weight of evidence. ${ }^{1}$

So strong is the faith in the epistemological importance of 'objectivity' that most participants in the debate over science and scientific knowledge during the last generation have made the possibility, or impossibility, of 'objectivity' the pivotal part of their argument. Both those who assert the power of science to uncover the generative processes of the nature ${ }^{2}$ and those who have called it into question ${ }^{3}$ actually share a common understanding of the nature of valid scientific knowledge. Both groups hold that scientists must seek to know the world "as it actually is" (Grove, 1989: 5). Both agree that assumptions - much less purposeful orientation to the object of study - 'interfere' with the perceptions of how things really are and so produce a distorted, a false, view of the world. Where the two camps disagree is not in their epistemological ideals, but in the belief as to whether or not this clear and unblinking vision of the world can be attained. The significance and moral force of the efforts of critics of science to deconstruct - that is to give an account of the construction - of scientific knowledge derives from the shared belief that valid scientific knowledge must be an 'objective', impartial representation of the underlying causal processes of the world.

\section{The Edinburgh School Understanding of Science}

For many, I suspect, these polarities - that we can either know Nature-as-it-is through scientific inquiry, or we can know nothing of Nature - are unsatisfying. My touchstone for resolving the arguments about science is the Edinburgh School approach as put forward in Scientific Knowledge: A Sociological Analysis (Barnes, Bloor and Henry, 1996). While ontological realists - they posit the world exists and has real causal processes independent of our perceptions - the Edinburgh School shifts our epistemological understanding away from scientific realism. Though often misread as a relativist position, Barnes Bloor and Henry's is a materialist argument (1996: 200-02) designed to create a causal explanation both for scientific success and failure (Breslau, 2007).

Firstly, Barnes, Bloor and Henry (1996) find the idea that people are unable to make sense of the world in any meaningful way frankly implausible - people's ability to act successfully in the world demonstrates we are capable of perceiving patterns and regularities in Nature. The simplest acts of everyday life - feeding rather than poisoning ourselves, getting through the door instead of crashing into the wall, or interacting successfully with other people - would be impossible if we could not find patterns in the phenomena of the world and from this experience develop successful practical guides to action. As they argue, people routinely accomplish practical tasks requiring knowledge of nature's regularities. To deny a causal role to accurate perception of the real world and ignore the fact that "sometimes

1 See http://en.wikipedia.org/wiki/Dragnet_(drama)

2 See for example, Gross and Levitt (1994) and Grove (1989).

3 See for example, Woolgar (1988); Collins (1992) and Collins and Pinch (1982). 


\section{Social Science and Social Struggle: Understanding the Necessary Confluence of Scholarship and Political Commitment}

our theories work unproblematically" would be to lodge ourselves in idealism of the most extreme sort (Barnes, Bloor and Henry, 1996: 32). ${ }^{4}$

The capacity to accurately perceive events and the occurrence of phenomena in the world is not enough, however, for Barnes, Bloor and Henry (1996) to accept that humans have the capacity to see the world 'objectively'. Objectivity implies more than a functioning system of sensory perception - it denotes an ability to make scientifically meaningful observations without interpreting them. They deliberately leave the contentious question of whether perception itself is influenced by assumptions to one side and instead argue that perceptions must be "transformed into observation reports before it can begin to enter into scientific knowledge" (ix) - before they become meaningful as scientific data. Observation reports - reports on what we have perceived - they argue, are always laden with assumptions, most derived from previous theoretical work: We must interpret what we perceive to make sense of - that is, explain - what we perceive: "[W]e cannot evade the responsibility of interpreting and understanding what we see" (Barnes, Bloor and Henry, 1996: 28). "Observations", in the sense commonly used, are "theory laden" (Barnes, Bloor and Henry, 1996: 2).

On the other hand, Barnes, Bloor and Henry argue "the notion of theory-ladenness [of the process of scientific observation] is misleading if it is used to downgrade the importance of observation..." (1996:92). "If observation is 'theory laden' ", they assert, then it is equally true that "theory is 'observation laden" " (92). They insist that the "general relationship of theory and observation is that of interaction" (92). The ability to perceive and the need to interpret what is perceived work together to allow us to operate in the world. "Interpretation," they assert, "is where nature and culture come together" (28).

Holding the notion of how 'observation' works to one side momentarily, it is useful to examine the Edinburgh understanding of the inherent limits to human knowledge. Here Barnes Bloor and Henry (1996) mount a direct assault on the belief that testing scientific explanations against empirical observation can lead to increasing levels of confidence

\section{It is worth quoting this passage at length:}

sociologists should be willing to acknowledge the existence and the causal relevance of the physical environment when they study the growth of knowledge...they should acknowledge the ability of individual human beings to monitor the physical environment and learn about it. Individual animals learn directly from experience. The psychologist's rat pushes the lever and looks to the arrival of a food pellet. If the pellet does not arrive, the rat gives every appearance of bafflement: it looks around, tries again, etc. The rat has learned to associate the lever movement with the arrival of food, and has developed an expectation that this association will continue in the future. The rat has successfully operated as an inductive learning machine; perhaps we should credit it with 'inductive reasoning'. In any event, it would be perverse to insist that what rats accomplish in this context, human beings cannot hope to emulate... It is more plausible to accept that the human brain, like the rat brain, may be profoundly affected by the reception of signals from the physical environment, and that these signals may directly engender not just perceptions and memories but associations and expectations as well (Barnes, Bloor and Henry, 1996: 76-77). 


\section{Social Science and Social Struggle: \\ Understanding the Necessary Confluence of Scholarship and Political Commitment}

in the veracity of our picture of the causal objects, forces and processes of the material world. However well tested or fruitful of technological innovation, they argue, scientific knowledge cannot lead us to sure knowledge of the underlying structures of the world for a straightforward reason: incorrect explanations often work quite well in the right circumstances for particular purposes: "There is no valid pathway from 'theory T works' to 'theory $\mathrm{T}$ is true'. The reason is simple: false theories can make true predictions; false premises can yield true conclusions" (Barnes, Bloor and Henry, 1996: 30).

It is not simply that our explanations may be 'imperfect'. No matter how successful they are, we can never know our best explanations are even on the right track in explaining the underlying causal processes at play. For an illustration of how useful scientific theories can be, even when we know they are not good representations of the underlying causal forces of the universe, it is productive to look at Physics, the very archetype of experimental science.

For almost three hundred years, Physics was dominated by the 'classical' work of Newton on motion and gravity. So much so that Newton's concept of the 'laws of motion' of the universe inspired a like phrase by Marx about capitalist development and the market models of liberal economists alike. Newton's work explained the motion of the planets and served as intellectual guide to the engineering innovation of the Industrial Revolution. His theory worked, and did so in exemplary fashion. But by the beginning of the twentieth century Einstein pointed out fatal problems with the explanatory power of classical physics' theory of light and Newton's understanding of motion and gravity. He began the theoretical work that produced what we now call 'quantum mechanics' and he developed the theory of relativity on his own - the two theories that replaced the Newtonian conceptions of classical physics. There is only one 'small problem'. As Einstein himself realized, quantum mechanics and relativity cannot both be true in the same universe - quantum mechanics denies any determinate process of cause and effect, while relativity embodies the classical notion of $\mathrm{x}$ causing $\mathrm{y}^{5}$. So far, the effort to develop a Theory of Everything that would replace this theoretical embarrassment has failed. However, in spite of their inadequacy as plausible depictions of the causal processes of the universe, quantum mechanics and relativity have been very scientifically fruitful. Quantum mechanics guided the development of the atomic and hydrogen bombs, and modern electronics. And relativity has met all the tests of its predictions regarding the behaviour of time, space, motion and gravity. Indeed, if the point - that scientific theories need not uncover the generative processes of the universe to work very successfully - must

5 Relatively assumes that every action can be traced, at least in principle, to a definite sequence of prior causes - as did Newtonian mechanics. Quantum mechanics argues that knowledge of prior quantum mechanical states of matter allows us only a probabilistic knowledge of future states; in other words we may know that $20 \%$ of the time the future state of the system in state A will be $x, 40 \%$ $y$ and the other $40 \%$ some distribution of $p, q$ and $r$. But what the next instance of transformation from state A will be is in principle unknowable. This amounts to saying that the normal notion of definitive causes and effects is invalid. 


\section{Social Science and Social Struggle: \\ Understanding the Necessary Confluence of Scholarship \\ and Political Commitment}

be made clearer, Newton's original theories have lost none of their practical usefulness either, providing very good working-approximations for relatively large masses moving at relatively low speeds - though Newton has been known for a century to be inadequate as an account of the underlying causal forces in the universe. ${ }^{6}$

How can this be? The Edinburgh School's bold and illuminating assertion is that all successful scientific knowledge is but various species of practical knowledge. Science has never achieved its grand aspirations to discover the ultimate properties of Nature and we have been very satisfied instead with obtaining useful knowledge of the world (Barnes, Bloor and Henry, 1996). Whatever our aspirations, we clearly define 'successful' and 'failed' scientific theories by how successful they work for our purposes:

A successful model [scientific theory] is not identifiable by the 'correct' matching of model and what is modelled in some abstract, disembodied sense. A successful model is a pragmatic accomplishment, something which those who evaluate it take to serve their purposes (Barnes, Bloor and Henry, 1996: 108-09).

....S]cientific research is conducted with references to goals and interests, and...both research and the evaluation of research must be understood as intrinsically goaloriented activities $(x)$.

What, then, is 'practical knowledge'? Practical knowledge is the sort of understandings produced by people in the ordinary execution of practical tasks in the world, the kind which all of us employ on a moment by moment basis to go about our daily tasks. Such knowledge must be empirical knowledge of the world in order to work, but it need not uncover the deepest causal forces at work - it must only be knowledge that incorporates accurate observations and assessments of the regularities of the interaction between the worker and his task, on the one hand, and the phenomena of nature that makes accomplishing that task possible on the other. Practical knowledge is thus both empirically and theoretically limited. It arises not from disinterested 'objective' observation but from accurate observation of the regular outcomes of the purposive interaction of the knower with the phenomena of the world within which she is operating. Practical knowledge arises from accurate observation from a viewpoint created by a purposive interaction with the world.

My favourite example of the nature, limitations and process of development of practical knowledge is my understanding of word processing. I don't like computers much, but I use my MacBook and Microsoft Word regularly and successfully to write my papers, articles and exams. I have developed an explanation of the connection between my actions on the keyboard and mouse and the regular production of letters and words on the screen (doing this will cause that). It seems to work reasonably well and must reflect the observable

6 See Bradley (2005) and Bohm (1971). 


\section{Social Science and Social Struggle: Understanding the Necessary Confluence of Scholarship and Political Commitment}

regularities of that interaction since it is reliably successful. But I would be less than truthful if I claimed to know the full properties of Word. And I know even less about the software and the hardware of my Mac that allows Word to work. My knowledge is thus both empirical and explanatory, and it works satisfactorily enough for my purposes. But my knowledge is strictly limited, both theoretically and empirically. In particular, the explanatory power of my knowledge is utterly inadequate to give an account of the Boolean logic circuits buried within the hardware of my Mac, much less the physical and chemical processes on which the operation of those circuits rely. But practical knowledge of how to use Word does not require that deeper understanding. I need only have a practical working knowledge of how to interact with the input and output devices of my Mac and of the properties of Word's interface with me, the user. This knowledge arose not from disinterested observation, but from my purposive interaction with Word as it runs on my Mac.

As practical knowledge goes, successful scientific knowledge is among the very best - the extent and intensity of the whole endeavour, and particularly of the testing process, ensures that. But it is not fundamentally different in kind than other forms of practical knowledge. But I am under no illusion my understanding of my computer penetrates to the underlying causal processes at play, if only because I know there are people who know a lot more than I do. Natural scientists don't have my advantage of knowing there are others who know more and better. They slide in their thinking toward the belief that if their theory works, it must be true in some deeper sense than practical knowledge. This is a fallacy towards which we all tend. In everyday speech, ${ }^{7}$ we all tend to assert our model of reality is reality itself, slipping over the proper distinction between our model of the situation and the still unknown causal forces at work in the world. As do atheists, theists, and social scientists. Barnes, Bloor and Henry argue that what natural scientists are doing by regularly insisting their theories uncover the real nature of the universe is what most of us do all the time, using a "realist strategy" of argument (1996: 81-84). All theoretical traditions are realist in form, Barnes, Bloor and Henry argue. Realist forms of analysis seek to explain the occurrence of the events and happenings of the world in terms of a few underlying categories of posited objects, forces and processes. Though the underlying objects, forces and processes posited by a theory are, in fact, only inferred by the analyst (as are their specific properties), 'common sense' realism tends to make scientists with successful theories imagine the gap between explanation and reality has been bridged. They argue their theoretical objects and processes are (ontologically) real. Indeed frequently they argue the 'underlying' forces, objects and processes of their explanation are in some sense more (ontologically) real than the empirical appearances of things. After all, that is what they passionately want to believe they have achieved. The problem, of course, is that such a leap is epistemologically unwarranted: “... false theories can make true predictions; false premises can yield true conclusions" (Barnes, Bloor and Henry, 1996: 30).

7 Barnes, Bloor and Henry (1996). 


\section{Social Science and Social Struggle: \\ Understanding the Necessary Confluence of Scholarship and Political Commitment}

To return to observation and 'objectivity', the realization that successful scientific knowledge is 'only' practical knowledge allows us to understand why the failure of humans to be able to view the world 'objectively' hasn't crippled us in everyday life, or in scientific inquiry. For in the pursuit of practical knowledge 'objectivity' has never been an issue. In practical activities our purposes are understood to structure our interaction with the world, and therefore to structure our experience of the world and the knowledge we attain of it. Our practical purposes don't prevent us from gathering knowledge, they "gear us into" the world ${ }^{8}$, shaping the interactions from which experience and practical knowledge arise. The acquisition of practical knowledge requires us to have purposes. Practical purposes are required to enable us to learn practical things about the world. Our inflated view of scientific knowledge arises because we aspire to gain so much more than practical knowledge, and our practical successes often mistakenly persuade us we have done so. The real irony here is that 'objectivity' could result in no knowledge at all. Praxis - the processes of engagement in practical tasks, the effort to infer likely reasons for our successes and failures, and the renewed engagement with one's task in the light of such reflection - is the only way we humans can develop empirical knowledge of the world.

The phenomenological approach of the Edinburgh School leads them to argue the processes of categorizing and classifying observable phenomena - the very basis of theorizing ${ }^{9}$ - are always matters of selecting what are thought to be the 'important' (relevant) characteristics of empirical commonality and difference in a trial and error fashion. The criterion of success is always a practical one - that such classifications are useful for our purposes. When problems arise with a classification, or a scheme of classification, so too does the opportunity to revise our judgment, and perhaps the basis of judgment, about relevant similarity and difference. The same is true of the understanding of causal relations between things - that is, theory itself (Barnes, Bloor and Henry, 1996). All these processes of interpretation are driven by trial and error - what Barnes, Bloor and Henry call "induction, from experience" (20). In successful instances of scientific theorizing the interpretation 'tried out' against perceptions - that is, our classifications and explanations - do not produce an obvious error in 'fit'. The interpretation that appears to 'work' at accounting for perception is the one the researcher then argues explains the matter at hand. Such fundamental dependence on the process of trial and error also accounts for the most common situation of theorists, namely that of the failure of a proposed explanation to work to account for observations. But theoretical 'fit', however successful, is only an instance of the development of working knowledge useful to accomplish specific human goals under specific conditions. Practical success cannot produce a sure understanding of the causal processes producing what we perceive. A change in conditions in the world, or a shift in our purposes, may well render our existing knowledge inadequate as guide to prediction

8 I want to acknowledge my colleague at St. Thomas, Dr. Colm Kelly, for my exposure to this phrase.

9 If theory is explanation, and explanation is of the form x causes $y$, then what x's and y's are is crucial to scientific explanation. 


\section{Social Science and Social Struggle: \\ Understanding the Necessary Confluence of Scholarship \\ and Political Commitment}

and human action.

Barnes Bloor and Henry also argue the common understanding of 'theory' is overblown. Rather than giving us clearly defined formal and logically coherent explanations, they follow Kuhn in arguing that a scientific tradition is really an assemblage of exemplary solved problems whose application to 'similar' cases is another practical - and problematic - accomplishment (Barnes, Bloor and Henry, 1996). We learn 'theory' as apprentices to a scientific trade by learning how to understand exemplary solutions and then to apply these models to the solution of 'similar' problems at the end of the Chapter in the textbook ${ }^{10}$. The ability to extend the concepts and metaphors from the exemplary solutions to ones assigned for solution on an exam in a manner satisfactory to the examiner is taken as evidence of having 'learned the theory'. Later, as a trained professional, a researcher's task is to apply these exemplars to new research problems for which nobody has yet found 'the solution'. The researcher must then hope their proposed solution 'passes muster' with the other members of the disciplinary community:

The scientist [in training] is initially taught exemplars, and learns to apply them to closely analogous problems directly, in a simple form of modelling. This is what happens in examples classes, or laboratory practice, or in exercises the student carries out in response to questions at the end of textbook chapters. In research, examples are similarly applied, this time to unsolved problems, and the same modelling skills acquired during training are put to use. The processes are similar; the crucial difference is in the evaluation of the processes, where in research, unlike in learning, there is no correct answer to be found at the end of the textbook. In research, the scientist must hope the analogy claimed between the solved and the unsolved problem will be an analogy found appropriate or attractive by fellow practioners, that there will be an agreement in practice amongst them all (Barnes, Bloor and Henry, 1996: 102-03).

The fact that scientific explanation is a creative, trial-and-error process of this kind helps us to understand why some scientists do better than others in successfully applying the insights to be derived from previous exemplary solved problems. Some people sift and interpret empirical evidence with greater clarity. Others may be more successful at using the stock of explanatory resources provided by the exemplary solutions. And others may be better at persuading others of their solution - success in a scientific career is very dependent on convincing others of the 'rightness' of one's use of an intellectual tradition. And scientific traditions are not static ${ }^{11}$ - the truly lucky add to the stock of theoretical resources in exemplary fashion. The 'facts' as we know them change, new cases arise, and new groups of people rise to influence in science in a way that ensures that - even within

10 I now appreciate the reason why my undergraduate professors assigned so many Math and Physics problem-sets every week during my undergraduate training!

11 Barnes, Bloor and Henry (1996). 


\section{Social Science and Social Struggle: \\ Understanding the Necessary Confluence of Scholarship \\ and Political Commitment}

a particular tradition of inquiry - today's verities may be seen as tomorrow's follies, and vice versa.

\section{The Social Sciences as Sciences in the Edinburgh Sense}

David Bloor's notion of the "strong programme" of the sociology of scientific knowledge (1991:7) specifically stated that what the sociology of scientific knowledge discovered about the physical and biological sciences must apply also to the social sciences. I would argue that, by the Edinburgh account, the social sciences are in the mainstream of scientific practice. The social sciences fit the 'form' and engage in the 'substance' of a science in a manner consistent with the Edinburgh School analysis:

- The social sciences do have exemplary solutions to explanatory problems that we learn as students, to which we make reference in teaching, and which we attempt to model in our own research. That's why one reads Marx, and/or others in one's tradition, and tries to understand the exemplary method(s) of conducting social analysis. We then try to creatively employ the realist concepts of the traditions in a creative, productive and persuasive fashion;

- Social scientists do creatively define and employ the realist concepts of their tradition to the explanation of unsolved cases of social behaviour, be those concepts those of the Marxist tradition (such as the mode of production, class, class exploitation, inherent class conflicts of interest, and class struggle etc), or those of our ideological opponents in the liberal tradition (such as infinitely greedy self-interested individuals, freeand-competitive markets, representative political institutions, equitable inequalities' based on occupation and effort, etc);

- Social scientists do attempt to provide causal explanations of the social world - to build theory - and to test it against observations we make of that world, even if few of the observations are made in the formal experimental setting;

- Social scientists do debate the adequacy of evidence and the theoretical interpretation put on it through the usual vehicles of scientific debate: at conferences, in journals and in books; and

- Social science research is indeed linked to practical goals and objectives. The distinguishing feature of the social sciences as opposed to the natural sciences - the many persistently co-existing strands of opposing theory - arises from the depth and the enduring character of the different political purposes held by social scientists.

It would be wrong to suggest that all social scientists pick their theories to achieve 


\section{Social Science and Social Struggle: Understanding the Necessary Confluence of Scholarship and Political Commitment}

certain political purposes. Many simply adopt those taught to them during their academic training. And experience suggests social scientists often use theories that don't well serve their purposes - the case which springs to mind being those who seek to resolve society's ecological contradictions with idealist or liberal modes of thinking. But the quickest way to demonstrate that political purposes are embedded in social scientific thinking - the differentiated political usefulness of theory - is to illustrate the uselessness of theories for some political purposes.

The easiest example for readers of Socialist Studies is the 'obvious' lack of utility of liberalism to suggest more than social democratic reform. Liberal social science proceeds from the assumption that existing institutions in 'free enterprise' liberal-democracies function with great efficiency and equity, making the case for the just and equitable character of present political and economic arrangements. Though liberals are divided along a spectrum between neo-liberals on the Right and social democrats on the Left ${ }^{12}$, they are in agreement on many points: 1) that free and competitive markets (at least 'normally') make for the best economic decisions; 2) that the rights of those who own property must be protected from 'undue' interference; and 3) that representative political institutions within a competitive market society make for an acceptable compromise between the need to draw on the 'wisdom' of those who manage society's institutions, and the rights of the nonexperts/non-elites to consent to the political and economic arrangements within which they live. The liberal assumption is that the fundamentals of capitalist society's institutions need to be preserved, and extended. This liberal set of concepts and its range of articulable disagreement are useless if you want to argue for the fundamental reorganization of the ownership and management of the economy and for a different system of government. Liberal social science simply was not designed to accommodate that political argument. For that purpose another theory, one that identifies capitalism's economic and political system as the source of injustice and misery is required, along with a potential mechanism of change.

That political purposes separate social science traditions is not incidental. Political concerns are central to the social sciences because they are central elements of the social life. We humans create, through our actions, the institutions and the practices that govern our lives. What creates and maintains and changes the organization of our lives and society are political struggles - in Mills' (1959: 6-7) statement of the "sociological imagination", who prevails? Many, many social arrangements are possible and most are not to everyone's advantage - for example, slavery. Or wage-labour. Questions of who wins and who loses from a social arrangement, and of how the shares of effort, risk and benefit are set up

12 Neo-liberals essentially argue that the economy is competitive enough, and the outcome of market operations are morally acceptable enough, that government should leave the economy and society to the 'forces of the market'. Social democrats argue the economy is too monopolized to expect the invisible hand of competition to work and that the degree of inequality produced by the market is too great. Government must regulate the market, provide a standard of universal public services, and redistribute income to provide a floor to poverty. 


\section{Social Science and Social Struggle: \\ Understanding the Necessary Confluence of Scholarship \\ and Political Commitment}

by particular forms of social organization, are important matters in the on-going social construction of society. Disputes over which social arrangement is a 'good' one, and over which ones are 'fair', arise as a matter of course amongst the members of a society. To study society it is to necessarily engage such matters of political and moral judgment. Divisions over these matters within the social scientific community have naturally led to, and sustained, different interpretations of society, social change and its desirability. ${ }^{13}$ Social scientists do not have a common goal for the future of society, nor do we identify uniformly with the social groups from which conflicting goals and evaluations emerge.

The 'embarrassing' feature of the social sciences - at least in discussion with natural scientists $^{14}$ - is the persistence of competing and contradictory ideologically based theories. Our efforts to test our theories against the evidence of the social world have not reduced the number of traditions by eliminating the ones found to be empirically on the 'wrong track'. There isn't even one track within the Left! I think we can extend Edinburgh School thinking to understand how the intellectual prowess and good sense of social scientists, not our inadequacies, are responsible for this:

\section{Enduring commitment}

Scholars are committed to their theoretical traditions in the way scientists are normally thought to be by Barnes, Bloor and Henry (1996). We do not give up our purposes, assumptions and cherished beliefs easily, and it is reasonable we do not. Purposes are necessary and enduring parts of human life, and theories difficult to build. It is not simple folly that leads people to put so much energy into sustaining their theory when it meets apparent empirical 'anomalies' in the world.

\section{Ambiguity of Evidence}

Not only is evidence - that is, the observations made - of the 'real world' of society fragmentary, incomplete and subject to differing interpretations, much of the available evidence about society and its history is ambiguous in its implications for theory. There are a lot of things 'going on' in the world, and evidence that seems to back a theory can usually be found as well as evidence that seems to confound or undermine it. For example: Sometimes groups of workers act collectively against their employers in the workplace (and more broadly). Often they do not. And sometimes they cooperate with the efforts of their employers. Such ambiguities in the evidence provided by the world not only poses challenges (that is, presents unsolved problems) for theoretical traditions, it can also provide resources for interpretations under attack from within or without their theoretical community.

13 See Sacouman (1999).

14 The interesting question is why natural scientists show a greater degree of unanimity about their purposes. My speculation is that they have near consensus on the ideology of Progress. Ask any natural scientist why they do what they do, and you will hear some variation on "It's neat stuff." If you then ask, "But why should we pay for you to indulge yourself in it?", you will receive some variation on, "We will deliver you Star Trek." 


\section{Social Science and Social Struggle: \\ Understanding the Necessary Confluence of Scholarship \\ and Political Commitment}

\section{The Creativity of Scholars}

People do not see only what they want. We are quite capable of discovering things are not working out as we expected - that is, that there exists a lack of empirical fit between what we expected to see, according to our theory, and what we do see. But people can be incredibly inventive at modifying a theory with new processes, objects and actors to account for these problems of 'fit' between the evidence of experience and their existing theory. Scholars are capable of considerable, and admirable, ingenuity at 'shoring up' a theory encountering anomalous observations in the world. This is important in the process of making theory more able to account for events that 'shouldn't happen' according to a 'simple' version of the theory. Unfortunately, these same abilities to create theoretical 'solutions' also keep flawed lines of thinking alive and vigorous long after they should be abandoned.

How then would the Edinburgh School theorists of the sociology of scientific knowledge evaluate the state of affairs in social sciences?

We cannot really be sure what the 'Edinburgh School' analysis would be, since Scientific Knowledge does not directly address the state of sociology and each 'application' of a theory is a creative act, an example of extending an analysis in a contingent fashion (Barnes, Bloor and Henry, 1996). However, I would surmise they would be unlikely to view the state of the art as representing a scientific failure. I would think that they would view the state of theoretical diversity in the social sciences (and history) as a natural reflection of the state of society and of the social science community itself. They would likely be affirmative of theoretical diversity, and skeptical about anyone's strong claims to really 'know' what is going on. And they would not expect the process of scientific debate to lead to a synthesis, or the disappearance of theoretical traditions, as long as the underlying generative social conflicts exist within society and amongst the members of the disciplines. I suspect they would readily understand why the most productive debates occur within political traditions of scholarship, and the many difficulties of talking across intellectual traditions rooted in different political purposes - something I wish to take up in the final section of this article.

\section{Implications for Our Practice as Scholars and Scholar-Activists}

At the most general level the Edinburgh School gives an intellectual imprimatur to what we have always known, or should have known, about how we operate as scholars and as scholar-activists. Our scholarly work involves a political commitment, and so does everyone else's. The Edinburgh School understanding allows us to recognize the normality of the political content of scientific knowledge and of the necessity for different theoretical understandings in the presence of different political purposes for knowledge. Fortunately, 


\section{Social Science and Social Struggle: \\ Understanding the Necessary Confluence of Scholarship \\ and Political Commitment}

the presence of those purposes does not represent an insurmountable barrier to empirical testing of rival explanations and predictions. Rival political assumptions are as discernable as rival evidentiary claims, political and moral goals are as inferable as other theoretical assumptions in research. Political assumptions and purposes are debatable, and debated, in the same ways as other matters concerning fact and interpretation. We regularly entwine political and empirical criticisms against the adequacy of theories that 'offend' us and we have always handled conflicting political intention and conflicting moral assumptions as part of social scientific debate.

So what difference does the Edinburgh perspective on science make, or what difference should it make, to how we practice our scholarly trade and engage in political argument as scholar-activists? Beyond the reassuring realizations the social sciences have to embody political purpose, that observation and interpretation cannot be objective, and that the social sciences will continue to be marked by conflicting traditions, does the Edinburgh School offer us any lessons for conducting our work? I believe it does.

David Bloor once pointedly asked me what working at the Science Studies Unit at Edinburgh had taught me, and I chose to sidestep a serious answer - it reduced the rhetorical power of the argument about the extent and consequences of ecological exhaustion I was trying to hammer home at the time. But we both knew I was avoiding the obvious. For the 'obvious' inference to be made from the work of the Edinburgh School is that we should be very skeptical indeed of strong claims to authoritative knowledge, and even to having the authoritative interpretation of a particular social scientific tradition. The Edinburgh perspective carries a strongly cautionary note. We cannot know what is going on with the confidence we often claim. It is misleading to pretend we do so, whether our 'audience' for strong claims is others or ourselves. There certainly are implications of that knowledge, ones that complicate an honest search for knowledge in the social sciences.

At the level of the individual scholar, the Edinburgh perspective makes it clear the scholarly endeavour is fraught with uncertainty. Evidence is incomplete and frequently full of paradoxes and problems, and its interpretation is always only a matter of educated guesswork. Explaining the evidence always involves trying to appropriate a complex and inherently 'fuzzy' set of intellectual resources to create a plausible account of what has happened and what might happen. There is no guarantee of knowing what is going on, or what to do - even if we belong to the best scientific tradition available to us. Any scholarly exercise necessarily involves a process of trial and error thinking where 'getting it right' is less likely than getting it wrong in whole or in part. We can easily be 'on the right track' and still be wrong. And there may well be more going on in the situation we are trying to explain than dreamed of in our theoretical frame. It stands to reason that humility is a reasonable attitude for a scholar in the face of such fallibility. The space between 


\section{Social Science and Social Struggle: Understanding the Necessary Confluence of Scholarship and Political Commitment}

confidence and inflated self-regard, and between defending one's arguments and listening to criticism, is difficult to navigate. It is not a sign of moral and intellectual weakness to know one is fallible and take account of it, to recognize when one is shown to be wrong and to learn from one's mistakes. In the face of the competitiveness of scholarly life, the Edinburgh School perspective carries a cautionary warning of the need to acknowledge one's fallibility and the tentative nature of knowledge.

The same admonitions hold true within what Barnes, Bloor and Henry call a "local interpretive tradition" (1996: 37), what usually is called a "school" within a larger intellectual tradition to which we belong. From the Edinburgh School perspective, the meaning of a tradition, its applicability, and the question of how to apply it to explaining a particular situation are all problematic. The Left is notorious for sectarianism, and what the Edinburgh School suggests is that the claims made by any school to have the authoritative interpretation of a tradition is implausible at best. Dogmatism is clearly misplaced in the light of the Edinburgh understanding of science, sectarianism a search for (false) certainty. The need to recognize that our models of the world are just that tentative, changing interpretations within a mere modelling of the world - is particularly important when new conditions are developing or new kinds of problems demand our attention. In these situations the limitations of even very successful knowledge are most likely to appear. For example, it has required rethinking of our time-honoured scholarly concepts to cope with the rise of gender and race issues to complicate class analysis. And the rise of ecological limits on production has forced us to reconsider evaluations of capitalist development, expectations of a future of material abundance, and with what material and social circumstances a socialist alternative must cope. The Edinburgh School perspective highlights the need to revise the way our intellectual traditions have been interpreted, how we use their intellectual resources, and our expectations of the future in the face of changing conditions and problems.

Science tries to identify the mistakes and the overconfidence of individual scholars and schools of thought through open publishing and debate. If sectarianism is no protection of scholarly certainty, what does the Edinburgh perspective indicate regarding the proper relationship between scholars in different 'local interpretive traditions' - whether they are schools of thought within one's own intellectual tradition (say Marxism), the Left more broadly, or in the camp of our political and ideological opponents? The real question I feel the Edinburgh perspective raises for debate across such barriers is "What are the grounds for productive debate within and between intellectual traditions in the social sciences?"

The scientific enterprise requires a high degree of trust to operate, trust not just in the competence of other scholars, but also in their honesty. Political differences can be corrosive of trust in the latter sense, even when objective differences in political goals are 


\section{Social Science and Social Struggle: \\ Understanding the Necessary Confluence of Scholarship \\ and Political Commitment}

relatively small. Large differences in political purpose are even more deeply corrosive. Questions of honesty may extend to whether people in the 'other camp' are willing to falsify evidence to support their case, in which case there can be no productive scientific interchange. The falsification of research findings - lying, in plain speech - is universally deplored. In the face of outright lies, the only answer is the best evidence we can find, and the charge that such a person cannot be trusted because they are liars.

More pervasive as a problem than lying is whether people are willing to be relatively upfront about their political and theoretical assumptions and intentions. Serious discussion across ideological traditions is rare because we seldom trust the political honesty and openness of our colleagues in other theoretical traditions. The same situation applies even to different 'camps' within an ideological tradition. There is often an active suspicion that 'they' are not honestly admitting or revealing their political agenda. This is not surprising. After all, there are mixed motives in operation in academic life - as scholars we are usually honestly seeking to know what is happening, but we are also suspicious of others' political purposes, and aware of the desire to advance our own. Matters are no made simpler by the fact one cannot easily distinguish between the honest social scientific disagreements and political propaganda disguised as social research. Both social research and propaganda make similar kinds of statements about the social world: this occurred, that did not: 'this' causes 'that'; this is "just" and that is not. The difference between social science and ideological propaganda lies in the intent (the purpose) of the author and the openness of the author to the criticism of her claims.

In cases where it is reasonable to assume we are dealing with scholarly debate, I feel the Edinburgh perspective suggests we should try to create mutual transparency of purpose, as we do in matters of research design and methods. We expect to know how evidence is gathered and interpreted and the theoretical framework being used. Is it unreasonable to expect a scholar to reveal the political and other purposes that inform her investigations? As social scientists we should find hidden political stances as unacceptable as undisclosed methodological techniques. Surely, the best stance towards ethical and political commitments in company of good will is to reasonably open, to hold others to the same standard, and to accept being queried on these matters ourselves. As the Edinburgh School makes clear, we cannot be 'objective', but we can seek to be honest observers and interpreters of society - to say things as we actually see them both empirically and in political context as best we ourselves understand it. And we can demand the same of others. If communication of this sort exists between people of different schools of thought, then the conditions exist for worthwhile scholarly discourse.

There is a related corollary: the virtue of a willingness to accept the scholarly legitimacy of competing political commitments amongst our academic colleagues. One cannot embrace 


\section{Social Science and Social Struggle: Understanding the Necessary Confluence of Scholarship and Political Commitment}

this Edinburgh view without accepting that we do not know what the correct theoretical tradition, or its specific interpretation, actually is. Commitment as a scholarly community to an 'open' discipline - one which exhibits broad tolerance for even fundamental disagreement on political and theoretical commitments - is therefore a scholarly virtue. Conversely, theoretical uniformity is more likely the consequence of political processes of dominance and exclusion than sound scholarship. There is a value to theoretical diversity in the scholarly ecosystem, as well as biodiversity in the natural environment.

Dealing with the pose of 'objectivity' in our role as public intellectuals is more difficult, for here our work is, in fact if not in name, political activism in the public sphere. Here we can hardly expect to begin what we have to say by pointing out just how limited and fallible our understandings of the world may be. Realism and realist strategies of argument (Barnes, Bloor and Henry, 1996) are expected of us, and it is the likely stance of all the participants. But we need not be crude realists. One can suggest that thinking of the matter at hand in this way, rather than that allows us to see the issues in the light which best explains the need for change, or the errors in our opponents perspective, or 'the real issue' at hand. Such forms of presentation suggest the realist case - this $i$ s how the world works - but admits of the truth that the same situation is viewed in different ways. Such a presentation allows one to make one's case in an honestly explained context of political and intellectual dispute. Good political argument in the public sphere over the long term involves shifting the ground of argument - of framing and reframing the question - and that requires one to explain the need to pick the best frame in which to theorize the problem. A questioning of political and intellectual frames, followed by a realist form of argument within one's frame may often be the most persuasive, as well as the most intellectually honest, form of presentation. Deconstructing the opponent's theoretical frame and evidence is hardly an innovation in practice, and it is a good jumping off point for reframing the question in terms that 'make more sense' of the situation, from our perspective.

Does the Edinburgh School perspective suggest a particularly efficacious means by which the power of conventional wisdom to claim the cloak of 'objectivity' might be challenged? Or how to disrupt the easy claim to epistemic authority that so often seems to accompany wealth and power? I do not believe so, for the simple reason these abilities are not rooted in epistemological problems. These abilities of conventional wisdom, and of those who employ it to their advantage, are rooted in their political power. Hegemony is a political process, not an epistemic mistake. What makes conventional wisdom appear to be 'objective' is the acceptance by the dominated of their situation as natural, if not 'just'. It would be idealism to expect that a theory of scientific knowledge would provide an epistemological shortcut to the undermining of the political legitimacy of the powerful and the social arrangements they work to sustain. 


\section{REFERENCES}

Barnes, B., Bloor, D. and J. Henry. 1996. Scientific Knowledge: A Sociological Analysis. London: Athlone.

Bloor, D. 1991. Knowledge and Social Imagery, Second Edition. Chicago: The University of Chicago Press.

Bradley, R. 2005. "Does God Play Dice with the Universe?" <http://www.sfu.ca/ philosophy/bradley/bradley.htm>.

Bohm, D. 1971. Causality and Chance in Modern Physics. Philadelphia; University of Pennsylvania Press.

Breslau, D. 2007. "Science and Culture.” In Blackwell Encyclopedia of Sociology. G. Ritzer (ed.). Blackwell Publishing, Blackwell Reference Online. Accessed Dec. 3, 2007 <http://www.blackwellreference.com.proxy.hil.unb.ca/subscriber/tocnode?id= g9781405124331_chunk_g978140512433125_ss1-38>.

Collins, H.M. 1992. Changing Order: Replication and Induction in Scientific Practice. London: Sage Publications.

Collins, H.M. and T.J. Pinch. 1982. Frames of Meaning: The Social Construction of Extraordinary Science. London: Routledge and Kegan Paul.

Eriksson, L. 2007. "Science, Social Construction of." In Blackwell Encyclopedia of Sociology. George Ritzer (ed.). Blackwell Publishing, Blackwell Reference Online. Accessed Dec. 3, 2007 <http://www.blackwellreference.com.proxy.hil.unb.ca/ subscriber/tocnode?id=g9781405124331_chunk_g978140512433125_ss1-47>.

Gross, P.R. and N. Levitt. 1994. Higher Superstition: The Academic Left and Its Quarrels with Science. Baltimore: The John Hopkins University Press.

Grove, J.W. 1989. In Defence of Science: Science, Technology, and Politics in Modern Society. Toronto: University of Toronto Press.

Marshall, G. (ed). 1994. A Dictionary of Sociology. Oxford: Oxford University Press.

Mills, C.W. 1959. The Sociological Imagination. London: Oxford University Press. 


\section{Understanding the Necessary Confluence of Scholarship and Political Commitment}

Newton, R.G. 1993. What Makes Nature Tick? Cambridge MA: Harvard University Press.

Ross, A. (ed). 1996. Science Wars. Durham, N.C.: Duke University Press.

Sacouman, R.J. 1999. Social Theory for a Change: Vital Issues in the Classics. Toronto: Irwin Publishing.

Tudor, A. 2007. "Realism and Relativism: Truth and Objectivity." In Blackwell Encyclopedia of Sociology. George Ritzer (ed.). Blackwell Publishing, Blackwell Reference Online. Accessed Dec. 4, 2007 <http://www.blackwellreference.com. proxy.hil.unb.ca/subscriber/tocnode?id=g9781405124331_chunk_ g978140512433124_ss1-30>.

Woolgar, S. 1988. Science: The Very Idea. London: Tavistock Publications. 